\title{
Feeling in Covid time
}

\section{María Pilar Ribate, Estela Sangüesa, Beatriz Giner, Laura Lomba, Clara Llanas, Cristina B. García}

Universidad San Jorge, Zaragoza, Spain.

\begin{abstract}
In this work, a Service-Learning project that consists of working on somatosensory and special senses stimulation in people with intellectual and/or developmental disabilities, is shown. This experience has been made through small and simple exercises, games or activities that allow these people to experience new sensations. The participants of this activity were students of one hand, Pharmacy and Education degrees working together and on the other hand, children of a special education school. The main aim is to develop the sensory and physical faculties and promote the functionality of the children with intellectual or developmental disabilities. The role of University students was to encourage the special school students to use their senses, applying the learnings of several subjects and collaborating with students from different degrees: Pharmacy and Education. Pharmacy students provided physiology concepts while Education students gave assistance and pieces of advice to Pharmacy students for carrying out the activities with the special school students. The sanitary situation obligates to develop this activity through video call. For both groups of students (university and school), this experience has been a different approach of learning and practicing using a new way of communication. All Pharmacy degree students thought that this experience has been good for their future professional activity. The teachers from the special education school indicated that these initiatives are very important for their collective.
\end{abstract}

Keywords: Physiological process; senses; intellectual disabilities; servicelearning; communication skills. 


\section{Introduction}

The pyramid of learning, developed by Williams and Shellenberger, shows the connection between the sensory system, the sensory motor development, the perceptual motor and the cognitive development (Fig. 1) $(1,2)$. All the captured and interpreted stimulus by our body structures are important for the development of the nervous system. Somatic sensitivity includes all processes that our body captures through the skin and skeletal muscles. Special senses like taste, smell, view and hearing allow to establish other important skills as social abilities especially in people with intellectual and/or developmental disabilities. Both are important in the first phases of human development. Children with developmental disabilities are more frequently observed to experience notable difficulties in sensory processing and motor skills development (1).

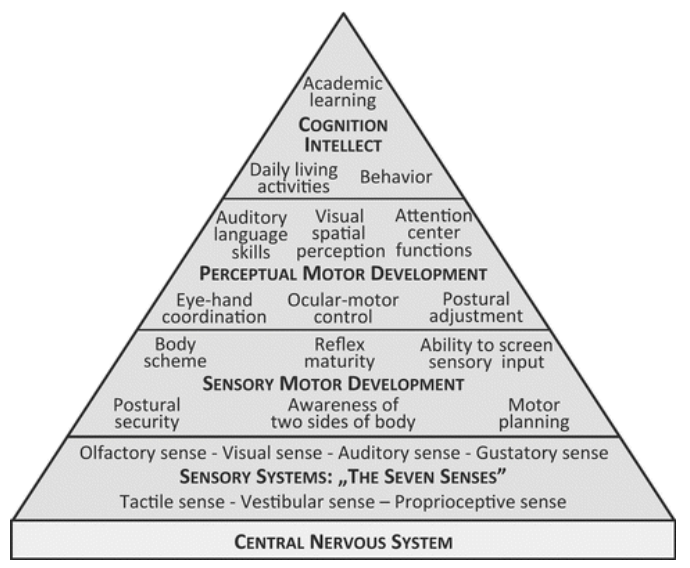

Figure 1. The pyramid of the human development Williams and Shellemberger. $(1,2)$

Taking into account this information, sensorial and motor systems should be stimulated. These physiological processes are included in the subject "General Physiology I" Pharmacy degree in San Jorge University.

In this project, higher education students (from Pharmacy and Education degrees) have prepared materials to stimulate somatosensory and special senses in people with intellectual and/or developmental disabilities from a special education school. Taking into account that the patient-health professional communication is a fundamental skill for health professionals (3), the university students had to learn how to use the prepared materials using adapted language for teaching students from the special education school. It is known that pharmacists, as health professionals, must be able to communicate with any type of person. However, communications between pharmacists and people with disabilities are scarce and normally, pharmacists lack of experience in this field. For that reasons, during this project, 
Pharmacy students received advice to adapt the materials from students of Education degree of San Jorge university.

The use of service-learning is considered as an important tool for the learning process in Spain (Opazo, 2016). This methodology allows to create a link between theory, practice and society (Rubio, 2011). Furthermore, a personal growth of Degree students is obtained through this activity. From this experience they can acquired different transversal and specific competences for their future professional activity. In service-learning the higher education is especially relevant for transforming our society into a more inclusive one (Martínez, 2008). The student participation, in a service-learning project, takes a special importance in their motivation. Some research suggested that service-learning methodology can be more motivating to students than traditional instructional methods (Ciesielkiewicz, 2018). These activities also stimulate students' curiosity for learning, which is indispensable in order to develop self-learning skills, as well as it contributes to the development of new knowledge (Ciesielkiewicz, 2018).

This Service-learning project has three principal objectives:

3. Improve the sensory capacities of people with intellectual disabilities.

4. to improve communication skills of future health professionals.

5. the use of new technologies for communication.

Due to the sanitary situation, it has not been possible to carry out the activity in person. To maintain safety regulations, this activity has been carried out through video calls.

\section{Methodology}

\subsection{Participants}

In this activity three groups of students have participated (figure 2):

- Group 1: 28 students of second year of Pharmacy degree studying "General Physiology I" subject. The role of these participants has been to prepare original materials to develop different senses using their physiology knowledge. Then they have made face-to-face video calls to show the usefulness of these materials to the group 3. The students were assigned into different subgroups.

- Group 2: 10 students of the last year of Education degree who were studying "Detection and intervention of difficulties in specific centers" subject. These students reviewed the materials prepared by Pharmacy students and made some comments about how to adapt the activities to the characteristics of people from special education school. 
- Group 3: 16 students of the special education school in Zaragoza (Spain). Their teachers provided information to the University students about characteristics of each child with intellectual disability to be taken into account for the design of the activities proposed by group 1 . There were children with different level of autism spectrum and intellectual disabilities.

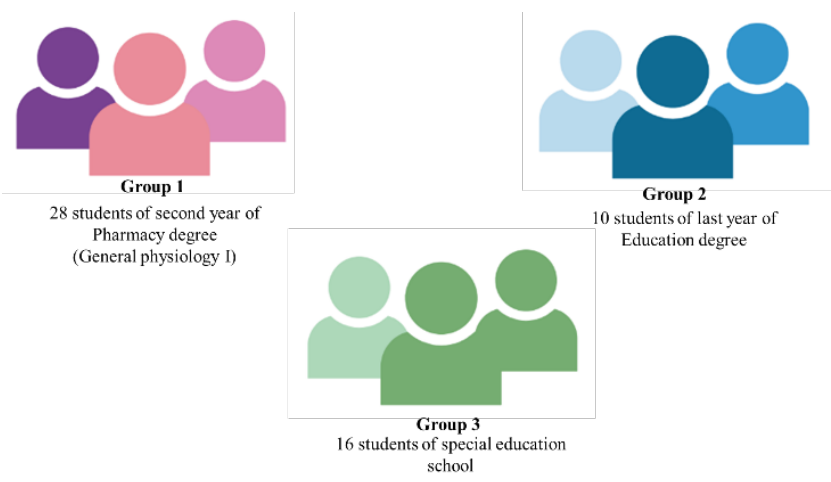

Figure 2. Participants in this project.

\subsection{Topics}

The work topics about somatic and special sense were:

- Visual sense.

- Tactile sense.

- Auditory sense.

- Gustatory sense.

- Tactile and proprioceptive sense and pain.

- Movement and vestibular sense.

Each subgroup from Group 1, has developed an online session with two students from the special education school, who had the same academic level. The students who worked with movement and vestibular sense used TiKToK mobile application to prepare their activity. The use of this tool allowed to carry out a more dynamic activity. Two groups worked visual and tactile senses, respectively, with children who had greater developmental difficulties. In relation to the tactile sense activity, the students have used materials with different textures and the children with their eyes closed had to identify them.

For preparing this activity, the Pharmacy students read several research papers related to sensory system and one of the disabilities (provided by the professor). These papers have been used for preparing the different activities. Each group have filled in a form explaining 
the activity (development, used materials and planification of video call). Then, this document has been sent to education degree students for providing their recommendations, proposals of improvements and new ideas for pharmacy students. Pharmacy students have prepared some activities and materials. One week before of the online session with special education students, all materials have been brought to special education school for isolating and disinfecting conditions. These sessions have been planned for one hour using TEAMS application (subgroup + special education student).

\subsection{Chronogram}

The activity was developed following the steps shown in figure 3.

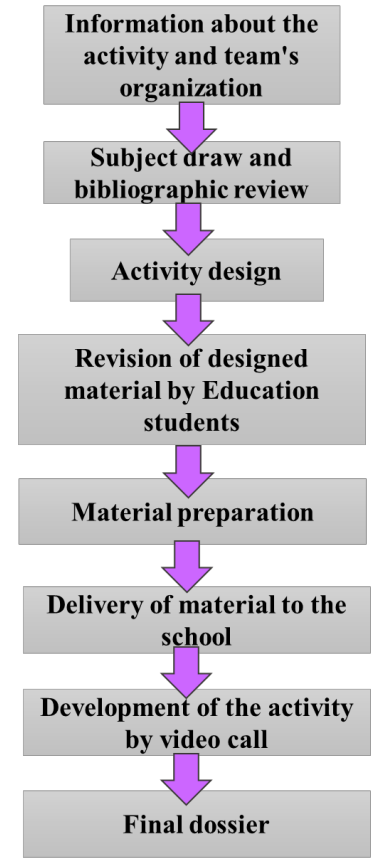

Manual with all information about activity was explained to the pharmacy degree students. Teams consisted of 3 or 4 students.

The topic was chosen at random.

The students prepared a file explaining their activity.

The Education students reviewed activity suggesting posible improvements.

The students development the activity materials.

The materials were delivered a few days before the activity to comply with all sanitary regulations.

"Face to face" session with students of special education school using video call.

Each group prepared a dossier with the information of their activity. In this document they included this information:

- An explanation of its physiological process.

- The reasons for the choice of these activities.

- Activity organization and roles of each member of the team.

- Didactic material used.

Figure 3. Steps of experience.

The evaluation of this experience has been made using rubrics. One rubric has been used for the activity evaluation (by the professor) and the other one to evaluate their groupmates work (students). 
Teachers from the special education school and Pharmacy degree students have been surveyed after this experience (Tables 1 and 2), using scores between 1 and 10 to evaluate these items.

Table 1. Questionnaire for teachers from the special education school.

1) Development of these activities has been interesting in the Education Centre.

2) Development of these activities has been suitable, and they have been well adapted to each student.

3) Activities have been well organized.

4) I would recommend repeating these activities in the future.

5) The overall rating for this activity would be...

6) Do you think that this kind of activities are positive for the inclusion of people with intellectual disabilities?

7) Do you think that these activities have changed University students' perception of people with intellectual disabilities?

8) Healthcare professionals know how to communicate with people with intellectual disabilities.

Do you agree with this statement?

9) Do you think that this methodology is effective for improving the communication skills of healthcare professionals with people with intellectual disabilities?

10) Materials provided by the University students have been well adapted and suitable.

11) Despite the current situation these activities have been well adapted compared to activities carried out in previous experiences.

12) It is better to develop this activity in person compared to video call.

Table 2. Questionnaire for Pharmacy degree students.

1) The information received to carry out the activity seemed correct to me.

2) The organization of the activity has been adequate.

3) I would recommend doing this activity in later courses.

4) I liked doing the activity.

5) The activity seemed appropriate and useful for my training.

6) I would have preferred to carry out the activity in person if the health situation had allowed it.

7) I believe that teaching innovation activities like this improve my teaching-learning process.

\section{Results}

28 students from group 1 have participated in this activity divided into 8 subgroups of 3 or 4 people each. All of them have prepared original and adapted materials to practice with somatic and special senses. Some of these materials are shown in figure 3. 


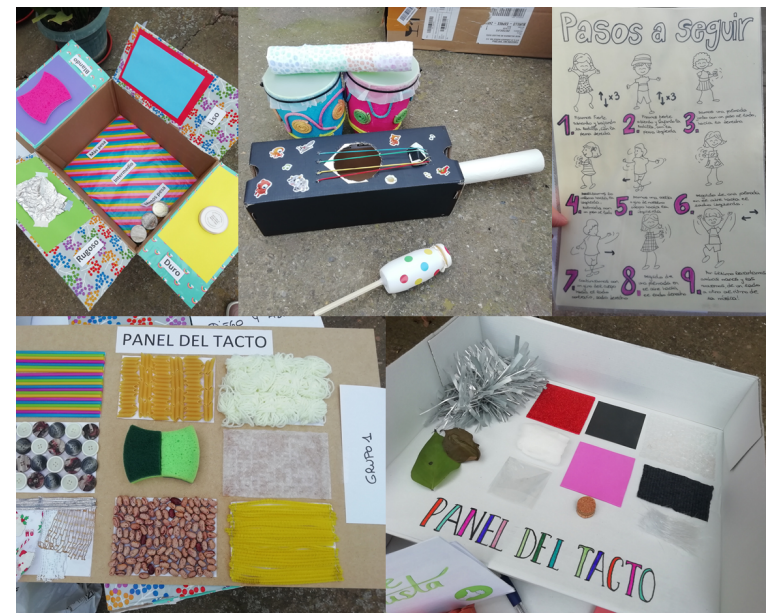

Figure 4. Materials developed by Pharmacy degree students.

Each subgroup made a video call of between 30 and 40 minutes with the two students from the school they were assigned (Figure 4). During the sessions, the Pharmacy degree students could interact with them. The 8 subgroups developed all the activities they prepared. In the case of Tik-Tok activity our students show how to coordinate the body movements using a popular song "Jerusalema". They guided them step by step during the video call with some dance steps. After this session they had to practice and record the video and then teach and rehearse the dance with the rest of the classmates.

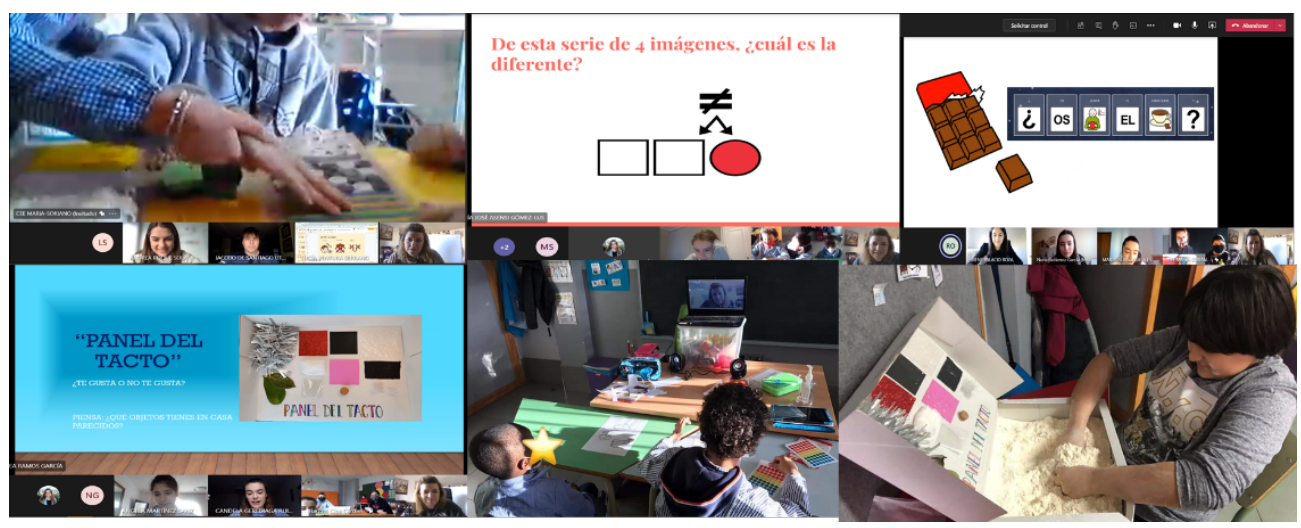

Figure 5. Video call during face-to-face sessions.

After the activity, a questionnaire has been completed by 19 Pharmacy degree students. 53\% of these students had not taken contact with people with intellectual and/or developmental disabilities before this experience. Different aspects of this activity have been evaluated (from 0 to 10 ) by students. All of them have stated that would have preferred to carry out the 
activity in person in case it was possible. Most students would recommend these kinds of activities in later courses (arithmetic mean $=9.47$ ) and recognized that they liked doing the activity (arithmetic mean $=9.4$ ).

In the evaluation of the activities by teachers from the special education school $(n=5)$, the arithmetic mean obtained from the survey ranged from 7.8 to 9.4. The lowest mark corresponded to the item about communication barriers of healthcare professionals in their relationship with people with intellectual disabilities. Mainly, they highlighted the adaptation of the activity to the current situation compared to previous experiences and the interest of this initiatives for the educational center. The psychological characteristics of the recipients of this project do not allow an objective assessment of their participation. Their expressions and behavior during different activities have been their subjective results. Only students with a lower degree of disability could be asked qualitatively for their opinion about this experience. All of them liked to participate in this project and they indicated that they had learned things that they did not know previously.

\section{Conclusions}

A positive impact of the activity has been recognized by all participants. Such experiences help University students to change and improve their communication skills with different possible future patients, in special with people with intellectual disabilities. Students from the school who were receptors of the activities could also understand and develop their own senses with new teaching materials. Besides, it is a different activity out of their routines.

The present situation caused by COVID pandemic has been a great challenge for the initiative developed in person during previous courses. Most students have expressed the difficulty of this experience by video call. Nevertheless, the main aims of the project have been achieved and there is a general perception of satisfaction by all participants.

\section{References}

Ciesielkiewicz, M., \& Nocito Muñoz, G. (2018). Motivation in service-learning: An improvement over traditional instructional methods. Teknokultura. Revista De Cultura Digital Y Movimientos Sociales, 15(1), 55-67. https://doi.org/10.5209/TEKN.58258.

Kanai, C., Toth, G., Kuroda M., Miyake, A., Itahashi, T. (2017). Social Skills in Autism Spectrum Disorders. In: Matson J. (eds) Handbook of Social Behaviour and Skills in Children. Autism and Child Psychopathology Series. Springer:Cham. doi:10.1007/978-3319-64592-6_13.

Martínez, M. (Ed.). (2008). Aprendizaje-Servicio y responsabilidad social de las universidades [Service-learning and social responsibility of universities]. Barcelona, Spain: Octaedro-ICE. 
Opazo, H., Aramburuzabala, P., Cerrillo, R. (2016). A review of the situation of servicelearning in higher education in Spain. Asia-Pacific Journal of Cooperative Education, $17(1), 75-91$.

Rajashree, K.C. (2011). Training Programs in Communication Skills for Health Care Professionals and Volunteers. Indian Journal of Pallative Care, 12-13.

Rubio, L. (2011). ApS: Aterrizaje entre teoría y práctica [S-L: Landing between theory and practice]. Aula de Innovación Educativa, 203-204, 34-37.

Williams, M.S., \& Shellenberger S. (1996). How does your engine run? Leader's guide to the alert program for self regulation. Albuquerque, NM: TherapyWorks. 